\title{
HABIT AND TEXTURE STUDIES OF LUNAR AND METEORITIC MATERIALS WITH A 1 MeV ELECTRON MICROSCOPE
}

\author{
J.C. DRAN \\ Centre de Spectrométrie Nucléaure et de Spectrométre de \\ Masse du CN R S., 91 Orsay, France \\ L. DURRIEU, C. JOURET \\ Institut d'Optıque Electronique du CN R S, 31 Toulouse, France \\ M. MAURETTE \\ Centre de Spectrométre Nucléare et de Spectrométne de \\ Masse du CN R S, 91 Orsay, France \\ Also :Laboratory for Space Physics, Washington University, \\ St Louis, Missour, USA
}

\begin{abstract}
Some habit and texture features of the finest and uncrushed grains in the lunar dust samples 10084 and 12070 , were studied with the $1 \mathrm{MeV}$ electron microscope of the Instıtut d'Optıque Electronique du C.N.R S., Toulouse, France These features were then compared with those observed in broken fragments extracted either from lurar rocks 10047 and 12063 or from different types of meteorites (Orgueil, Pesyanoe, Shergotty) The finest fractson of the Apollo 11 lunar soll samples is constituted of about $80 \%$ of well ordered but rounded crystals which are frequently overlaid by a thin skin of amorphous matenal. In the Apollo 12 soil the grains are coarser, the fraction of crystallıne material is higher ( $90 \%$ ) and the proportion of crystals showing an amorphous skin is smaller, but both lunar soil samples are very different from meteontic or lunar rock matter. Some implications of the present results concerning the fabric of the finest fraction of the lunar regolith, the ancient solar wind and meteoritic research are briefly outlined.
\end{abstract}

\section{Introduction}

It is known [1,2] that habit and texture studies of well dispersed materials can provide informations conceming their fabric. In particular texture features such as the distortion present in the electron or $\mathrm{X}$-ray diffraction patterns of natural samples have already been used to obtain information about the disordenng processes acting durnng their formation and subsequent history [3-5].

Samples from the surface of atmosphereless and magnetic field free planets like the Moon - and possibly the parent body of gas-nch meteontes - have been irradiated by solar and galactic cosmic rays, and by solar wind particles, and also subjected to vanous types of dynamic processes, such as meteontic impacts. As a result various forms of lattice disorders should be stored in such samples and their habits and textures should reflect their complex history in the planet regolith.

800,200 and $100 \mathrm{keV}$ transmission electron microscope studies have been reported [6-11] for grains extracted from the Apollo 11 lunar soll and from lunar rocks. These studies have been generally limited to the analysis of exsolution lamellae present in lunar pyroxenes and have given evidence for a fast cooling history of these crystals and for disordering processes probably not related to the irradiation history of the lunar soil. 
In the present work we studied some habit and texture features of the Apollo 11 and 12 uncrushed dust grains by high voltage electron microscopy, with the hope of finding some characteristic signature of the dynamic processes acting in the lunar regolith and evidence for the exposure of the grains in different types of solar radiations.

We saved a tremendous amount of machıne tıme by not studying in detal exsolution lamellae and not indexing our great number ( 2300 ) of electron diffraction patterns. This decision was made because we were using the diffraction patternsalmost exclusively as "scalıng" devices to estımate the relative abundances of amorphous material and well crystallized and highly disordered crystallıne grains in the finest fraction of both lunar soll samples, and because the study of exsolution lamellae only gives a crude classification of pyroxene grains in groups of related cooling histories.

We then compared the lunar soll results to those obtained from the study of small crushed crystals extracted from various types of meteorites and from the surfaces of lunar rocks 10047, 12063. Such comparisons were made in order to get both a better understanding of the fabric of the finest lunar soll grains and some clues concerning the history of meteoritic matter considered either as primitive (Orgueil) or extremely enriched in solar type rare gas (Pesyanoe).

\section{Experimental Methods and Results}

\subsection{Experimental methods}

Lunar fines from the Apollo 11 and 12 missions samples 10084 and 12070 - and small surface chips from lunar rocks 10047 and 12063 were provided by NASA. Small fragments from the type I carbonaceous chondrite Orguell, from the solar type gas-rich Pesyanoe enstatite achondrite and from the Shergotty eucrite were obtained from B. Mason (U.S. National Museum, Washington D C.).

The preparation techniques applied to the samples differ from those described in a previous paper [12] concerning the nuclear particle track content of the same lunar soll grains The finest fractions of the lunar soll samples were still separated by using a 400 Mesh sieve but they were directly "dry" deposited with a platınum loop on a new parloidion-carbon substrate containıng microscopic holes (FukamıAdach type substrate). As they were coarser and opaque to the beam the crystals extracted from lunar or meteoritic rocks were crushed before being also "dry" deposited.

The samples were examined with the $1 \mathrm{MeV}$ electron microscope of the Institut d'Optique Electronique du C.N.R.S., Toulouse. Generally dark field and bright field observations and electron diffraction patterns were made as soon as possible after the introduction of the grain in the microscope, with a beam intensity smaller than $0.2 \mu \mathrm{A}$. But we examined occasionally the influences of both the beam intensity (up to $2 \mu \mathrm{A}$ ) and the duration of the observation (up to $2 \mathrm{hr}$ ) on the appearance and stability of some of the most strikıng habit and texture features of the grains

\section{Experimental results}

Our habit and texture studies are summarized in figs 1-6 of this paper where we show the high voltage electron micrographs and electron diffraction patterns of the Apollo 11 and 12 uncrushed lunar soil grains (figs 1-3) and those of broken fragments extracted from the following meteorites Pesyanoe (fig. 4), Shergotty (fig. 5), and Orgueil (fig. 6). In addition, several high voltage electron micrographs of individual grains from the Apollo 11 and 12 soils can be examined in figs. 1-5 of another paper [12] for a more detaled comparison of lunar and meteoritic matter, in that paper the Apollo 12 grains were crushed. We analyzed about 100 individual grains for each lunar soil sample, $\sim 50$ grains for each lunar rock but only $\sim 10$ grains for each meteoritic sample Therefore the conclusions concerning meteoritic matter have to be considered as very preliminary.

\subsubsection{Lunar fine samples 10084 and 12070}

In the Apollo 11 dust, the crystalline component represents approximatively $80 \%$ of the material and has the following striking characteristics.

(1) The grain habits are generally very homogeneously rounded (dark grains in fig. 1),

(2) In dark field observation an important fraction of the grains ( $\sim 50 \%)$ appear to be surrounded with a superficial layer of about $1000 \AA$ in thickness. We verified that these layers, also observed in the Apollo 12 grains, were made of amorphous material by moving the selection diaphragm over the grains and 

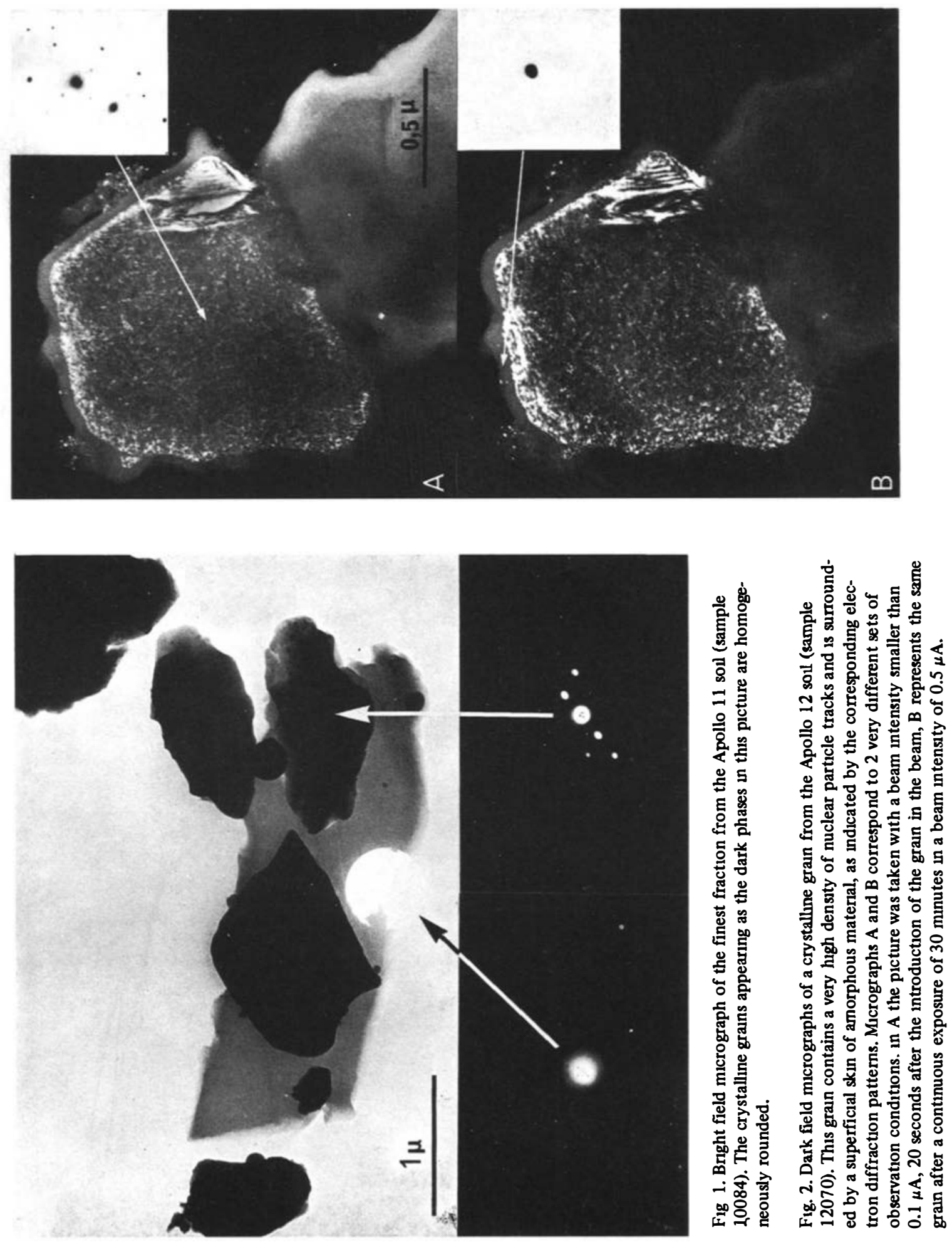

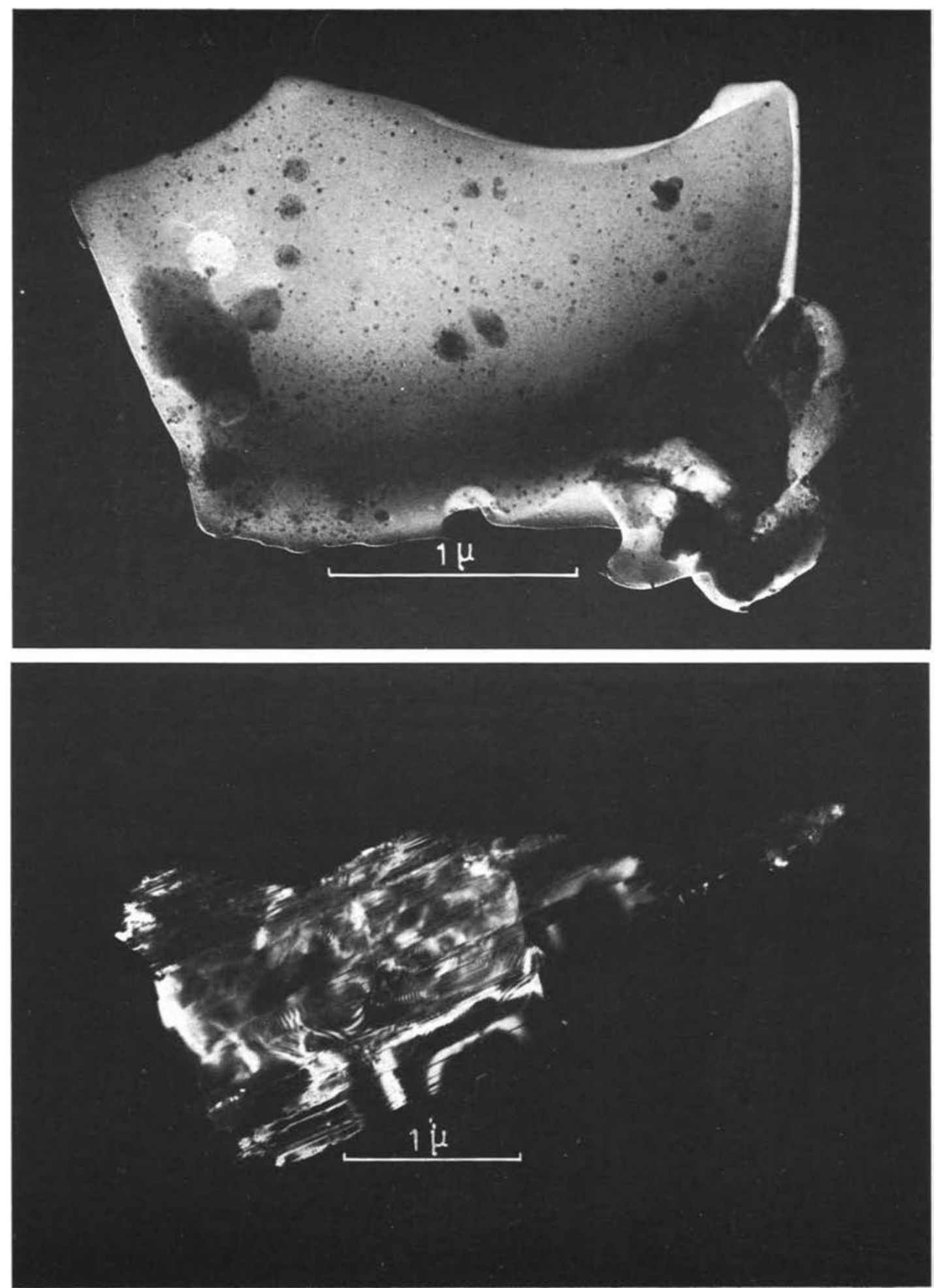


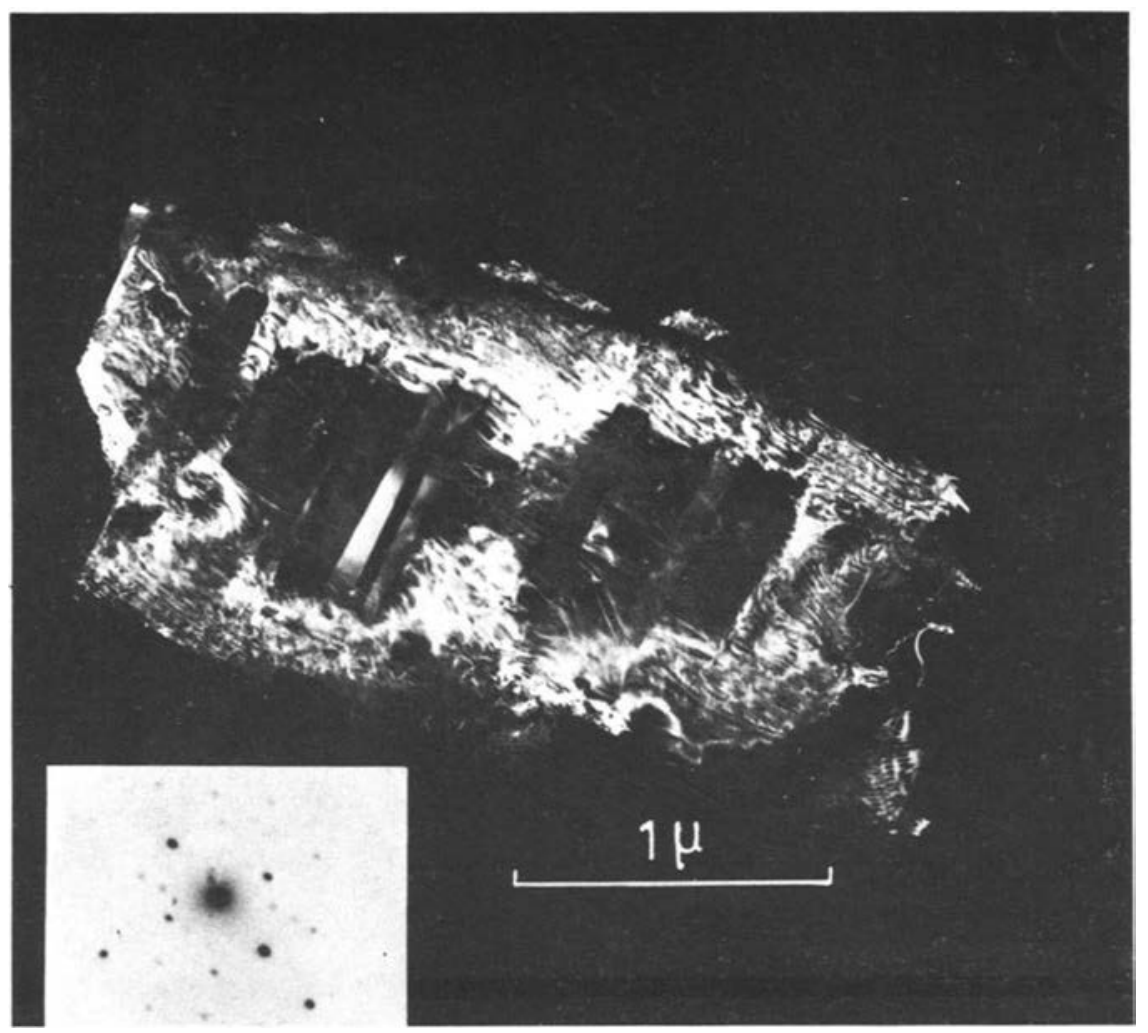

Fig. 3. Dark field micrograph of an amorphous grain of the Apollo 11 lunar soll. This grain was examined with a contrast screen and is beautifully rounded.

Fig. 4. Bnght field micrograph of a crystalline grain extracted from a dark part of the gas-rıch Pesyanoe meteorite.

Fig 5 Dark field micrograph of a crystallıne grain from the shocked Shergotty meteorite. Abundant texture features are visible in almost each individual grain 


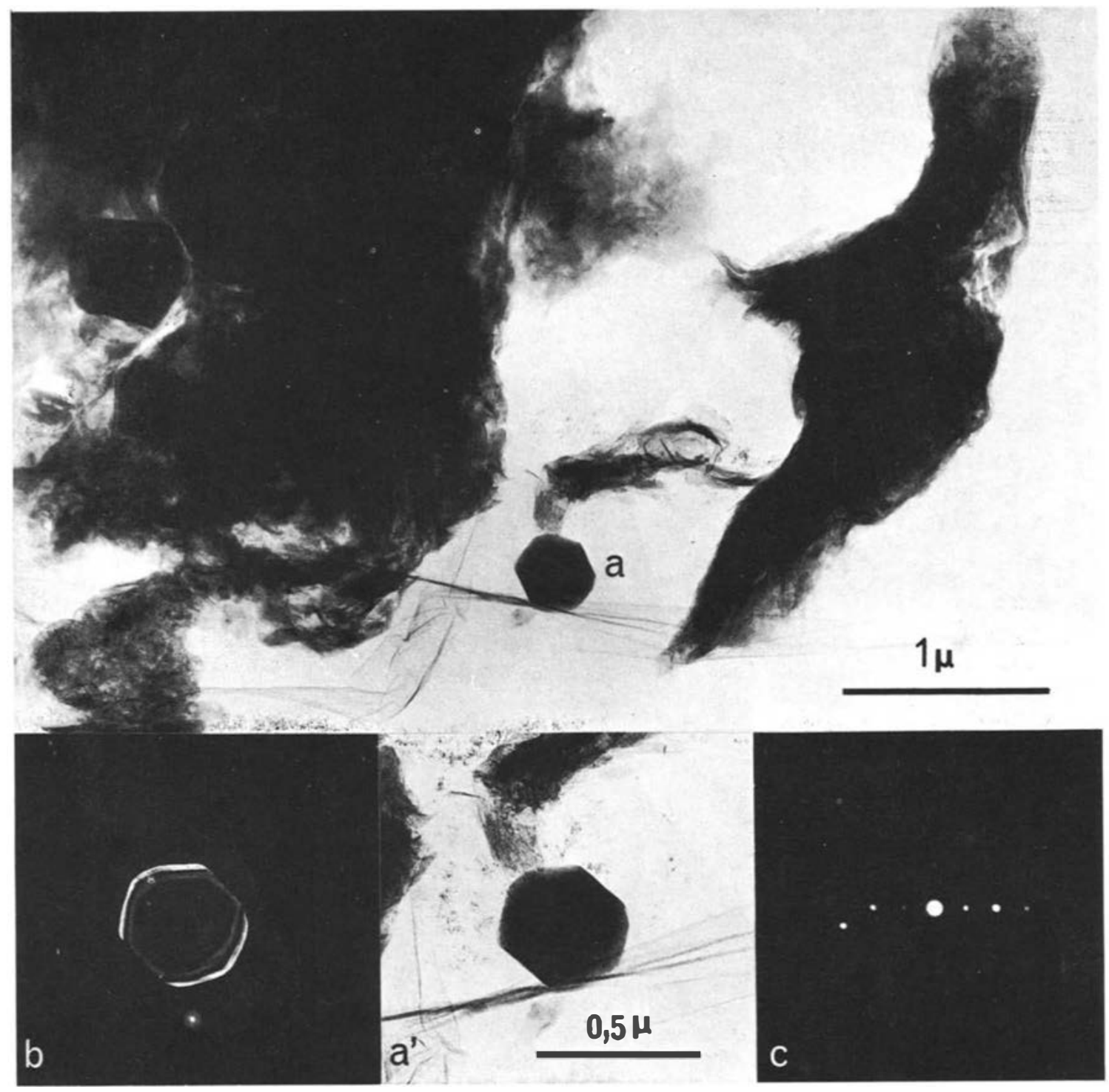

Fig. 6 Bright field micrograph of the fine grained matter extracted from Orgueil by a gentle crushing In the lower part of this picture magnified views of the dark and bnght field observations of spherule $a$ have been reported in $b$ and $a^{\prime}$ with the corresponding electron diffraction pattern in $c$. This pattern indicates that the spherule is probably a circular magnetite platelet. No latent track can be observed in the good dark field micrograph $c$ which shows a complicated growth pattern for the platelet 
observing that the electrons were no more diffracted when the selected diffractıng area (of about $1000 \AA$ in diameter) was chosen in the dark superficial lining. Such an amorphous skın and the corresponding electron diffraction patterns are shown in fig. 2, for an Apollo 12 grain, which was simultaneously studied for other purposes described in paragraph (3),

(3) The diffraction patterns when taken below the amorphous skın, show a good ordering of the grain lattices; thus the proportion of highly disordered crystalline material is remarkably small in thus sample,

(4) A very high proportion of the crystalline grains ( $90 \%$ ) contain very high densities of nuclear particle tracks perhaps produced - as suggested in another paper [12] - by a flux of cosmic nuclear particles with energies intermediate between those of the solar wind nucles and those of the solar flare cosmic rays It should be pointed out that the highest track dens1tes $\left(\gtrsim 10^{11}\right.$ tracks $\left./ \mathrm{cm}^{2}\right)$ were always observed in grains showing an amorphous skın

The non crystalline component representing the remaining 20\% fraction in sample 10084 is totally amorphous and consists of very thin lamellae which are either verr angular (light grain in fig. 1) or very homoge asly rounded like the crystalline grains (f., J).

Some of the characteristics of the finest fraction of the Apollo 12 soll were different from those of the Apollo 11 soll In the Apollo 12 dust sample the proportion of crystalline material was higher ( $90 \%$ ) and that of crystalline grains showing an amorphous skın was smaller ( $20 \%)$. Furthermore the grains were coarser and for unknown reasons, the nuclear particle track distributions were more contrasted and easier to observe in the Apollo 12 material

In the discussion we shall explain how the amorphous skin could be used as a tracer to study the past activity of the Sun. But for such a purpose it is necessary for this skin to be formed on the Moon and not in the microscope as a result of the interaction between the electron beam and the grains $\mathrm{A}$ beam or1gin for the skin is ruled out by the following evidences, (1) the skin was never observed on crushed fragments extracted from lunar or meteoritic rocks, (2) its thickness and appearance did not vary when the beam intensity, $I_{\mathrm{b}}$, was increased by a factor of 10 or when the duration of observation, $T$, was extended up to 2 hours, therefore the skin cannot be a contamination or a radiation damage layer* (the lack of any combined effect of $I_{\mathrm{b}}$ and $T$ is illustrated in fig. 2 where we show two micrographs $A$ and $B$ of the same grain taken with the following values for $I_{\mathrm{b}}$ and $T$. fig. $2 \mathrm{~A} I_{\mathrm{b}} \lesssim 01 \mu \mathrm{A}, T \sim 20$ seconds, fig. $2 \mathrm{~B}$. $I_{\mathrm{b}}=0.5 \mu \mathrm{A}, T=30$ minutes, (3) 1ts thickness or appearance showed no discontınuity when the observed grains suddenly stopped being supported by the Fukami-Adach substrate, this fact excludes any complicated shadowing effect for the skin origin, due for example to the deposition of grain matter on the substrate

Some additional observations relevant to the origin of the skin were made

(1) The skin was still observed unchanged after an annealing of 1 hour, at $800^{\circ} \mathrm{C}$ in air followed by a very rapid transfer of the grains in the microscope column, this observation seems to rule out the skin as a reaction layer produced by an atmospheric component with the grains, and indicates that the skin matter is not made of pure glass because after this annealıng experıment we have not found any spherule or glass lamella in the 400 Mesh residue,

(2) It disappeared completely after 1 minute of etching in a mixture of acids (2 parts $\mathrm{HF} 40 \%, 1$ part $\mathrm{SO}_{4} \mathrm{H}_{2} 80 \%, 4$ parts water) at $25^{\circ} \mathrm{C}$, such etching conditions generally remove layers of about several $1000 \AA$ in thickness in sllicate material and this experıment shows that the skin is superficially located in the grains

\section{Lunar and meteoritic rocks}

Texture features such as exsolution lamellae, striatıons, microcrackings were much more frequent in crystals extracted from the surface of lunar rocks 10047 and 12063, but no amorphous edge with high track densities below was observed

The grains constituting the dark parts of solar type gas-rich meteorites are considered by several investiga-

* The degradation of insulator grains [13] and the very quick fadıng of latent nuclear particle tracks [14] in silıcate minerals occur frequently at $100 \mathrm{keV}$ and these effects are generally attributed to the ionization produced by the electrons in the samples That they are not observed at $1 \mathrm{MeV}$ is not surprising in view of the marked decrease in the ionization energy losses of the electrons and the much lower beam intensity required to make similar observations with the $1 \mathrm{MeV}$ microscope 
tors to have been individually irradiated in the ancient solar wind [15] and solar flare cosmic rays $[16,17]$. In grains extracted from a dark part of a typical member of this class of meteorites (Pesyanoe) we observed no amorphous fraction and no gradual disordering of the crystals. The angular habits (fig. 4) were similar to those of fragments obtained from the crushıng of large single crystals No amorphous edge with nuclear particle tracks below was identified in the crystallıne grains.

Shergotty is generally considered as a good example of a shocked meteorite [18] We observed that the material extracted from this meteorite was extremely different from the lunar soil grains and the Pesyanoe material. An important fraction ( $250 \%$ ) of the grains was amorphous and a gradual disordering of the crystalline component was observed, however no amorphous edge or track was present in the grains. Furthermore abundant texture features, rarely found in the lunar fine and Pesyanoe materials were observed in almost each individual grain chosen at random (fig. 5)

The Orgueil meteorite is often described as a very primitive object [19] The material extracted by gentle crushing from this meteorite (fig 6) was markedly different from the Apollo 11 and 12 dust grains as well as from the Pesyanoe and Shergotty matter (a) the proportion of amorphous material was even more important ( $290 \%$ ) than in Shergotty. However the abundant texture features observed in the Shergotty grains were almost absent in the Orgueil material, (b) the habits of the amorphous fraction were frequently similar to those of "fibrous" material, (c) no crystallıne grain with an amorphous edge and latent tracks below was found in Orgueil, (d) small crystalline spherules were frequently observed The indexation of the electron diffraction pattern of the spherule shown in fig. 6 indicated a cubic lattice similar to that of magnetite Therefore these spherules are probably circular magnetite platelets of a type already discovered by Jedwab with an optical microscope [20]. No spherule with diameter smaller than $3000 \AA$ was observed.

\section{Discussion of the results}

\section{Fabric of the lunar soll grains}

The fabric of the finest fraction of the lunar regolith is very different from those forming the grains extracted from a primitive meteorite (Orgueil), a solar type gas-rich meteorite (Pesyanoe) or a shocked meteorite (Shergotty) because this fraction, contrary to meteoritic matter, seems to consist of 2 distinct components which are a totally amorphous fraction and a component of rounded crystalline grains showıng no tendency for a gradual amorphization These grains are frequently homogeneously rounded and covered by a thin skin of amorphous matter and loaded with very high densities of nuclear particle tracks

Furthermore in the smallest grains of the lunar soil the exsolution lamellae and other striation and microcracking features were apparently less frequent than those observed by us and other investigators [6-11] in coarser lunar rock crystals, in particular in those examined with a $800 \mathrm{keV}$ electron microscope, after an ion bombardment thinning of the crystals [6] This observation could be added to other evidence such as the 3-to 100-fold enrichment of the lunar soll in $\mathrm{Ir}, \mathrm{Au}, \mathrm{Zn}, \mathrm{Cd}, \mathrm{Ag}, \mathrm{Br}, \mathrm{B}$ and $\mathrm{Tl}$ relative to type $\mathrm{A}$, $B$ rocks reported by Keays et al [21] - to argue that an important fraction of the lunar soil did not originate from the rocks imbedded in it presently

The finest grains of the lunar regolith were probably produced by an erosion mechanism releasing matter from rocks by a flaking off process perhaps triggered by micrometeorite impacts as suggested by Gault [22]. Such a process can in principle produce an amorphous fraction but also well crystallized and highly disordered crystalline materials Then the astonishingly small proportion of highly disordered crystals observed in the present work should help to fix some of the input parameters (such as the characteristics of the ancient micrometeorite fluxes) in Gault's theory.

Immediately after their release in the lunar soll the grains probably had angular habits limited by cleavage or fracture surfaces. Then they should have been processed by a second erosion mechanism having the strikıng capabilities of homogeneously rounding the grain habits and covering their external surface with a skın of amorphous material without introducing any measurable amount of lattice disorder below the skin.

It is difficult to admit that these erosion features observed in grains of about 1 micron in size are due to micrometeorite impacts, or to microcracking in- 
duced by thermal shocks produced durnng the lunar thermal cycle A more likely process is perhaps the implantation of solar wind ions in small grains which are rolling over the Moon surface during their bombardment. That such an implantation is really occurring is clearly shown by the rare gas data of Eberhardt et al [23]. Then the amorphous skin ob. served in the grains could be due to the radiation damage accompanying the ancient solar wind implantation. This conclusion is also compatible with the skin thickness ( $\sim 1000 \AA$ ) which corresponds to the expected range of solar wind ions in silicate materal

\subsection{Anclent solar wind}

If further studies* confirm the solar wind origin of the amorphous skın then some interestıng results concerning the characteristics of the solar wind in the past could be obtained for the following reasons.

(1) In a given mineral the thickness of the skin will represent a dynamic balance between the loss and the formation of amorphous material but will be a function of the range and therefore of the energy of the solar wind particles Thus it should be possible to look for eventual marked variations in the average energy of the solar wind nucles in the past by measurnng in a given mineral species (such as cristobalite which can be easily identified by its electron diffraction pattern) the thickness of the amorphous skın as a function of depth in a core tube,

(2) for a given set of exposure conditions of the dust grains on the Moon surface, any change in the solar wind intensity in the past would result in a variation with depth inside a core tube of the proportion of grains showing a skin effect,

(3) for a given mineral grain the critical value of the solar wind flux above which the amorphous skın is produced can be determined by artıficially irradiatıng lunar material with solar wind type ions. This value will give an interesting lower limit of the integrated flux of solar wind nuclei which bombarded the lunar soll grains.

\footnotetext{
* Crushed grains from the central part of several lunar rocks are presently artificially irradiated with solar wind type lons and the eventual growth of the amorphous skin will be studied as a function of the energy, atomic number, dose rate and integrated flux of the ions
}

\section{3. Meteoritic research}

The first solar type gas-rich meteorite grans we examined looked very different from the lunar soll grains both in the size distribution of the grains, which were much coarser, and by the absence of an amorphous fraction Also there was no rounded edge showing a superficial amorphous skın with high densities of tracks below. These differences have already been emphasized by our high voltage electron microscope nuclear particle track studies [12] and by other evidence summarized elsewhere [24]. They show that the individual mineral grains in the dark part of a typical solar type gas-rich meteorite have not been processed by mechanisms similar in nature or in intensity to those responsible for the irradiation and formation of the finest grains of the lunar regolith, except if the compaction process anneals the tracks and the amorphous skin without introducing any measurable amount of disorder in the lattice of the grains

These conclusions are also valıd for Orgueil However it could be argued that this meteorite contans crystals which have been highly disordered by some kınd of radiation damage. Therefore before excluding an ancient irradiation for the constituent grains of Orgueil, a thermal annealıng experıment of a type proposed by Seitz et al. [25] should be conducted to verify if the proportion of highly disordered crystals has clearly decreased after the annealing, thus indicatıng that radiation damage remnants are still trapped in Orgueil, even if no amorphous edge with tracks below has been preserved in the mineral grains of this meteorite

As already pointed out the results and conclusions concernıng meteoritic matter are prelımınary because we examined only a small number of grains $(\sim 10)$ in very few meteorites. A more extended version of our work, including results obtained from a $2 \mathrm{MeV}$ electron microscope survey of different types of primitive meteorites (Orgueil, Murray, Renazzo, Bjurbole), other gas-rich meteorites (Pesyanoe, Khor-Temıkı, Jodzie, Kapoyeta) and the fission xenon rıch Angra dos Reis eucrite, is in preparation

\section{Acknowledgements}

This work has been made possible by the generous cooperation of Professors G Dupouy and F. Perrier 
from the Institut d'Optıque Electronique du C.N R.S., Toulouse. The efficient help we received from R. Sirvin, B. Saur and G Gontran of the same Institution is gratefully acknowledged. One of us (M. Maurette) is deeply indebted to Drs R. Bernas and R.M. Walker for their very active and enthusiastic support and interest.

\section{References}

[1] M. Figlarz, F Vincent, C. Lecaille, J Amiel, Sur les notions d'habitus et de texture des solıdes pulvérulents, in: Powder technology (Elsevier, 1968) p. 121

[2] P B Hirsh, A Howie, R B. Nicholson, D.W Pdshley, M.G Whelan, Electron Microscopy of Thin Crystals (Butterworths, London, 1965)

[3] J F Kerridge, The use of selected area electron diffraction in meteorite mineralogy, in Meteorite Research (IA EA, Vienna, 1968)

[4] S S. Pollack, Disordered pyroxene in chondrites, Geochim Cosmochum Acta 32 (1968) 1209.

[5] R R Jaeger, M E Lipschutz, X-ray diffraction study of kamacite from iron meteorites, Geoclum. Cosmochım. Acta 32 (1968) 773

[6] S.W Radcliffe, A H. Heuer, R M Fischer, J M. Cristie, D T Criggs, High voltage transmission electron microscopy study of lunar surface material, Science 167 (1970) 638.

[7] J C Balley, P E Champness, A C. Dunham, J. Esson, W S Fyfe, W.S. Mackenzie, E F. Stumpfl, J Zussman, Mineralogical and petrological investigations of lunar samples, Science 167 (1970) 592

[8] H Fernandez-Moran, S S Hafner, M Ohtsukı, D Virgo Mossbauer effect and high-voltage electron microscopy of pyroxenes in type B samples, Science 167 (1970) 686

[9] M Ross, A E Bence, E J Dwornık, J R Clark, J J. Papike, Lunar clinopyroxenes, Science 167 (1970) 628

[10] P E Champness, G W Lorimer, Lunar pyroxenes, Microscopie Electronique, vol. II (1970) 639

[11] W L Bell, G Thomas, High voltage electron microscopy of Moon rock and other materials, Conference on the applications of high voltage electron microscopy, Harwell, April 1970

[12] J. Borg, J.C Dran, L Durreu, C. Jouret, M. Maurette, High voltage electron microscope studies of fossil nuclear particle tracks in extraterrestrial matter, Earth Planet Sc1. Letters 8 (1970) 379

[13] J.D C. McConnel, Photochemical degradation of a sillcate in the beam of the electron microscope, Phil. Mag 20 (1969) 1195.

[14] P B Price, R.M. Walker, Observations of charged particle tracks in solids, J. Appl Phys. 33 (1962) 3400

[15] P. Eberhardt, J Geiss, N. Crógler, Further evidence on the orign of trapped gases in the meteorite KhorTemikı, J. Geophys. Res 70 (1965) 4375

[16] P Pellas, G. Poupeau, J C Lorın, H Reeves, J Audouze, Primitive low energy particle irradiation of meteoritic crystals, Nature 223 (1969) 272

[17] D. Lal, R S. Rajan, Observations relating to space urradiation of individual crystals of gas-rich meteorites, $\mathrm{Na}$ ture 223 (1969) 269

[18] J A Wood, Physics and Chemistry of meteorites, The solar system, vol IV (1963) 337

[19] B Mason, The carbonaceous chondrite, Space Science Rev 1 (1963) 621

[20] J Jedwab, La magnetite en plaquette des meteorites carbonées d'Alars, Ivuna et Orguel, Earth Planet. Sc1 Letters 2 (1967) 440.

[21] R R Keays, R Ganapathy, J C Laul, E Anders, G F Herzog, P.M Jeffery, Trace elements and radıoactivity in Lunar rocks, Science 167 (1970) 490

[22] D E. Gault, Meteoroid environment and age relationships for the lunar and martian surfaces, Nato Advanced Study Institute, The Moon and Planets (Newcastle, April 1970).

[23] P Eberhardt, J. Geıss, H Craf, N Crögler, U Krahenbuhl, H Schwaller, J Schwarzmüller, A Stettler, Trapped solar wind noble gases, $\mathrm{Kr}^{81} / \mathrm{Kr}$ exposure ages and $\mathrm{K} / \mathrm{Ar}$ ages in Apollo 11 lunar material, Science 167 (1970) 558

[24] G Crozaz, M. Maurette, R.M. Walker, Nuclear track studies of ancient solar radiations and dy namic lunar surface processes, Nato Advanced Study Institute, The Moon and Planets (Newcastle, April 1970)

[25] M. Seitz, M Wittels, M Maurette, H. Heckman, Mıneral irradiations and implications to lunar and meteoritic materials, Radiation Effects (1970), in press 